\title{
A Proposal of the New System Model for Nursing Skill Learning Based on Cognition and Technique
}

\author{
Yukie Majima $^{1,2}$, Yasuko Maekawa ${ }^{2}$, Masato Soga ${ }^{3}$, and Masayuki Sakoda ${ }^{1}$ \\ ${ }^{1}$ Graduate School of Engineering, Osaka Prefecture University, Osaka, Japan \\ ${ }^{2}$ College of Sustainable System Sciences, Osaka Prefecture University, Osaka, Japan \\ \{majima, yasuko_m\}@kis.osakafu-u.ac.jp \\ ${ }^{3}$ Faculty of Systems Engineering, Wakayama University, Wakayama, Japan \\ soga@center.wakayama-u.ac.jp
}

\begin{abstract}
It is necessary to acquire not only specialized knowledge but also appropriate nursing skills in nursing education. In this paper, we propose an elearning system model to support a high level of technique learning, such as "tacit knowledge" and "proficient art" in nursing skills, which have been heretofore learned only from experience. This e-learning system enables selflearning in addition to intellectual learning, thereby enhancing knowledge of procedures and understanding of nursing skills. The results of evaluation experiments showed that each system had learning effects. However, simultaneously, they indicated the importance of the capability of self-training with actual trial-and-error to acquire skills. For that reason, adding "check point learning" to the already developed cognitive learning support system as a new function, we made improvements to provide nursing skills training covering detailed items. Based on this, we propose step-by-step learning after completing learning in the cognitive domain through spiral learning, which is the first step (from intellectual learning support to skill learning support again to intellectual learning support), learners move on to the second step (technique learning support) in a phased manner. We think that other evaluation given by instructors by checking between the first and second steps, as well as checking self-leaning, reduces the sense of loneliness, which is a common pitfall an e-learning, and which provides satisfaction with self-learning outcomes and a motivation for additional learning development.
\end{abstract}

Keywords: Nursing skill, E-learning, Cognition, Tacit knowledge, Finger motion capture.

\section{Introduction}

Medical care as it is practiced today is highly sophisticated and specialized, as represented by genetic medicine and transplant medicine. Furthermore, against the backdrop of changes in social structure, the diversity of people's lives and quality of life, and the diversity of patient needs, it is readily apparent that people demand health and medical services that ensure their safety and security. Because of the progress of 
aging society, with fewer children and more numerous elderly people who must be cared for, the importance of nurses is becoming increasingly recognized. In Japan, nursing education is being taught increasingly in universities at a rapid pace: the number of programs offered increased from 11 universities in 1991 to 200 universities in 2011. Because of the lack of nursing teachers, efficiency and quality improvement in nursing education have become daunting challenges.

It is necessary to acquire not only specialized knowledge but also appropriate nursing skills in nursing education. Nursing skills are direct actions with a sense of purpose for security, comfort, and self-help of subjects based on specialized nursing knowledge. They reflect practitioners' views of nursing and levels of skill acquisition [1]. Nursing skills of different types are classifiable into classes such as "skills for living assistance", "skills for assistance associated with medical care", "skills for interpersonal relationships", "skills for developing the nursing process", "skills for hearth assessment", and "skill for education and advice".

Intravenous injection, which draws much attention among all nursing skills, is related to body invasiveness by inserting a needle and infusing medicine into a blood vessel. In recent years, after the change of the new administrative interpretation to "intravenous injection conducted by a nurse is treated as a category of auxiliary action of medical treatment" in Japan (Health, Labour and Welfare Ministry, 2003), it has been noted that education related to intravenous injection must be improved (Japanese Nursing Association, 2003). Consequently, nursing students are now required to master the skills to administer intravenous injection safely.

Nevertheless Hagi et al. [2] reported that "self-learning of intravenous injection" and "technical training in college" are less useful for skill acquisition of intravenous interjection of new nurses, presumably because few students feel that learning at college is useful in a field or because new nurses tend to be passive in skill acquisition. Moreover, "reviewing one's own failure" and "knowing one's own tendency by personal experience" are described as highly valued factors for skill acquisition. Therefore, encouraging a support system to enable a nurse to review personal failures and ascertain personal tendencies is important.

In many cases, the evaluation of nursing by patients tends to base on whether nursing skills are good or bad. For example, we often hear it said: "That nurse is good at injections", or "That nurse is sloppy, so I do not want her/him to wipe my body clean." It is necessary for learning support to make nursing skills understood and to make them familiar. Inaba [3] states: "Embracing both the scientific (knowledge), which skills themselves have, and the humane (mentality) sides, nursing skills are a specific and meditating instrument that actually embodies role functions of nursing." It can be said that nursing skills that people being treated evaluate here incorporate not only the mere accuracy of procedures, but also something like the invisible atmosphere surrounding each nurse, including interpersonal relations skills that produce tender-ness and politeness and an ethical perspective that includes respect for others. Such empirical knowledge and technique that cannot be verbalized are called "tacit knowledge [4]". We can learn more from tacit knowledge than we can learn from what we can verbalize. 
In this paper, we propose an e-learning system model to support a high level of technique learning, such as "tacit knowledge" and "proficient art" in nursing skills, which have been heretofore learned only from experience, and also to enable selflearning, in addition to intellectual learning that deepens procedures and understanding of nursing skills.

\section{Theoretical Background}

In conventional classes designed to teach nursing skills, instructors first explain the purpose, necessity, and procedures of nursing skills in lectures and then demonstrate them in technical seminars. Nursing students gain skill training individually or in a group in a series of learning processes. In skill training, even if the students sometimes teach each other in a group, they often put questions directly to the instructor. However, few teachers can answer their questions adequately on the scene. Therefore, students might be unable to gain nursing skills sufficiently within college classes, given present conditions.

In nursing education, learning using videos is well known to be effective. Libraries of nursing training institutes have numerous nursing skills video materials. Watching corresponding materials is often necessary as a task before the class. For novices, imaging of procedures using videos is effective to make learning go smoothly. Today, because of the development of information and communications technology, including the internet, e-learning and learning support systems incorporating nursing skills videos have been increasingly introduced into the field of nursing education [5]-[9].

The definitions of e-learning vary. The Japanese Ministry of Economy, Trade and Industry (2005) defines it as "independent learning using communications and networks based on information technology; the content is edited according to learning objectives. The interactivity is ensured between learners and content providers (Information Services Industry Division, Commerce and Information Policy Bureau, Ministry of Economy, Trade and Industry)." Majima (2005) defines it as "what is provided in a learning environment using ICT, and a form of learning which can be provided solely by self-learning or collaborative (group) learning or in combination of them [10]." E-learning in the field of nursing skills education often aims to make students learn procedures and grounds of skills. Jacqueline B. et al. report that (computer-assisted learning versus conventional teaching methods on the acquisition and retention of hand washing theory and skills in pre-qualification nursing students), learning with computers is at least as effective as face-to-face learning [11].As described, studies of learning support using videos to learn procedures have been actively conducted in nursing skills education, but almost no studies exist on learning support systems to learn proficient techniques (art).

Regarding techniques in nursing care and their verbal description, Tanaka [12] argues that "Even if one forcibly verbalizes techniques (techniques that can be transformed into formal knowledge such as manuals) that have already been verbalized, techniques which can be verbalized but have not been verbalized yet and techniques which are impossible to be verbalized (non-verbalizable techniques), by their nature, cannot be used unless each nurse understands the circumstances of each case and the 
other individual party, namely patients. Put another way, for some knowledge (tacit knowledge), verbalization is apparently completely meaningless." (emphasis added).

To date, we have examined "nursing techniques which can be verbalized but which have not been verbalized yet". We have also begun to analyze characteristics of skilled nurses' techniques in intravenous injection techniques; it has begun with methods and the line-of-sight in practice. Results revealed that line-of-sight flows differed between novices (nursing students) and experts (nursing personnel) and that experts move their lines of sight to the next practice (prior treatment). Many nurses believe that once they have identified a vein, they are able to perform an intravenous injection. They often verbally express the moment when they have done it well as "feeling like entering a blood vessel 'smoothly ('sutto' or 'kukutto' in Japanese)'”. Nonetheless, they consider that it is difficult to express exactly how they feel. In contrast, novice nursing students consider that the knack for techniques is to remember procedures. It is therefore important for the process of learning support to compel novices to master procedures before their advancement to sharing the performance characteristics of experts.

Using medical simulators is also effective to acquire skills. There are widely diverse medical simulators available. In recent years, an increasing number of training centers are using dolls to master lifesaving emergency treatment through experience, costing 10 million yen or so per doll [16]. However, such training is not available to all learners, and its cost performance is far from good [17]. This does not also teach items such as tacit knowledge that nursing skills have. To clarify tacit skills and knacks included in nursing skills [18] and support to learn them, we have produced a system with which learners can conduct self-learning for the two sides - the intellectual side [19] [20] [21][22][23] and the technique side [24][25]. Now we are verifying the system [26].

\section{System Supporting Cognitive Learning of Nursing Skills}

\subsection{System Configuration}

This learning support system aims to acquire nursing skills through self-evaluation and self-reflection. The system has four learning functions as follows:

(1) Skill procedure study function: Identification of one's own skill's procedures

This function enables nursing students to learn technical procedures. Nursing students understand that the knack of skills should be to conduct the procedures precisely, suggesting that learning methods allowing learners to remember the procedures among others are good for them. Figure 1 below shows that this function is a type by which a user can confirm procedures by checking a radio button.

(2) Skill video comparison function: Comparison of model images with one's own technical images

This is a function by which a user can work with two video images simultaneously or alternately to compare them. If the learners use this function, then they are helped by 
comparison to experience and consider the difference of time between that required by a skilled nurse and by themselves.

(3) Reflection function: Comparison of each image in one's own practice progressions

With this function, nursing students can enter text while answering questions. Learners can think by themselves through comparison and freely describe what they have found. It helps learners to promote their reflection and think by writing using the system. The questions are set so that learners can make a comparison in every procedure of intravenous injection.

(4) Portfolio function: Output and identification of learning results

With this function, users output the procedures that they have input by themselves or described what they have found. It is also used as a portfolio of the process of skill acquisition, by which the learners can be conscious of their own findings and can thereby advance their own learning.

\subsection{Evaluation}

Results of two verification experiments using the system are explained in 3.2 .1 and 3.2.2.

\subsubsection{Evaluation of the Acquisition of Nursing Skill Procedures}

We asked that five nursing students use the system to learn intravenous injection skills and examined their usefulness. The skill evaluation was conducted at three times: (1) pre-testing, (2) testing after practicing self-skills training, and (3) testing after practicing the learning support system. Results show that four students became able to insert a needle into a vein correctly at stage (2), but mistakes in the procedures had not been corrected. Results showed that the improved intravenous injection skills, such as performing correct procedures and correctly injecting medicine into a vein, were identified in stage (3) [22].

\subsubsection{Acquisition of Tacit Knowledge Included in Nursing Skills}

Another evaluation experiment was conducted with another 16 nursing students. Scores for nursing skills increased significantly among the group who performed reflective learning with the system compared to the group (control group) who did not do any learning [23]. When we examined the action of "releasing a tourniquet after selecting a blood vessel and fixing the tourniquet again after wearing gloves and preparing for disinfection", which is not included in procedural manuals (only included in model video images) and sought to reduce the burden on patients, students other than the control group showed great improvement. It was verified that learning with the learning support system was useful to learn tacit knowledge and actions contained in the videos [26]. However, with regard to the "identification of a reverse blood flow (whether or not inserting into a vein)", which is an item to notice, all the control 
group tried to identify a reverse blood flow in the experiment this time, but only one person was actually able to insert an injection needle and identify a reverse blood flow. The results described in 3.2.1 revealed that a reverse blood flow was identified through self-skills training alone. Therefore, it is readily apparent that the effect of skills training strongly influences the acquisition of techniques to insert an injection needle and identify a reverse blood flow: taking skills training was found to be necessary in technique acquisition, even actually trying and failing [23].

\section{$4 \quad$ System Supporting Technique Learning of Nursing Skills}

\subsection{System Configuration}

Based on the verification results of the system supporting cognitive learning, we developed a system to support technique learning [24] [25].

This system is intended to build a learning-support system using virtual reality by reproducing finger movements used in practicing nursing techniques. Those reproductions can then be used by later generations to show the non-verbalized part of nursing techniques that have heretofore only been learned from experience. We have already developed a prototype system to acquire finger position data when a syringe is grasped. The system was used for practicing blood drawing techniques with a finger motion capture system. Using the acquired data, it reproduces the practicing process of the techniques three-dimensionally.

\subsection{Evaluation}

We asked seven nursing students to use the system. Their opinions after completing the experiment were positive overall in terms of learning support by the system. However, because it takes $30 \mathrm{~min}$ to put on finger sensors, the development of devices to obtain data more easily, including devising a way to repair the sensors, has become a challenging task [24][25].

Subjects participating in the evaluation experiments learned about the cognitive learning support system in advance, in which instructors gave comments individually, with viewing of nursing skills video images in the post-test when they were wearing the finger sensors. The following characteristic comments were made as their opinions after completing the experiment.

"I think that lessons are important as knowledge for processes such as memorizing procedures. However, using a computer helped me review my techniques from different perspectives, such as video images, and helped me to compare them with others. I understood what I had been unable to understand in class."

"For the parts which could not be recognized by the learning support system, I think that it is better to receive advice or instruction from a third party, such as a teacher, to understand the contents well. In some cases, it might be difficult to learn by self-learning alone." 
"It is better to have advice from teachers after having looked back and considered matters individually. Without some review, I think that the consciousness (about the lesson) will fade."

These opinions suggest that the order of learning, doing technique learning after reflective learning, and setting up an opportunity to receive guidance from teachers between the sessions of learning, in addition to self-training, will engender the improvement of learning enthusiasm and the enhancement of learning effects.

\section{$5 \quad$ E-learning System Model Supporting Self-learning from Cognition and Technique Sides in Nursing Skills Acquisition}

Although some skills can be learned with knowledge that is prescribed in a manual, it is difficult to learn nursing skills, which include implicit knowledge, as physical knowledge, according to a manual. Knowledge acquired from experience or practice could be called experiential knowledge, or "Deep Knowledge" (meaning the expertise or special skills which proficient engineers or managers accumulate from their various experiences). For learners to obtain such knowledge, they must acquire, experience, and reinforce that knowledge through additional learning including practice, observations, problem resolution, and experiments, especially under the guidance of instructors [27].

In the field of nursing education, the chances for learners to gain skills through onthe-job training (OJT) in clinical training are offered. In the field of college education under the pressures of several instructors or times, however, it is not easy to use OJT for the learning of various skills. In addition, because nursing students have many skills to learn, it is difficult for them to take much time to master any one of them. Consequently, to support them in acquiring nursing skills, we shed light on what is an effective learning-support method and examine the skill-learning support model.

The acquisition process of nursing skills is said to comprise three phases by which the improvement can be promoted: "the phase of knowing", "the phase of mastering", and "the phase of using". New nurses learn practicing intravenous injections through first "following the instructors' model," "benefiting by their experience," and "repetitive practice". Additionally, in a traditional learning method, at first, it is common that the nursing student imitates the technique of an expert nurse [29]. In other points of our previous study [18], we found that linguistic expressions differed among nurses in terms of the sensation of fingers that nurses recognize at perceiving blood vessels by touch or inserting a hypodermic needle, which suggests that formal knowledge by visualization would be better than that by verbalization to share and use know-how of nursing skills which cannot be verbalized.

The results of our previous evaluation experiments indicated the importance of the capability of self-training with actual trial-and-error to acquire skills. For that reason, adding "check point learning", "skill procedure study", "skill video comparison", "reflection", and "portfolio" functions of the already developed cognitive learning support system as a new function, we make improvements to provide nursing skills training covering detailed items (Figure 1). We think that technique acquisition at the tacit knowledge level can be attained by learning in the following order: 1) doing cognitive learning of knowledge and procedures of nursing skills; 2) repeating 
self-skills training until one becomes capable of practicing correctly; and 3) repeatedly following experts' finger movements using the technique learning support elearning system.

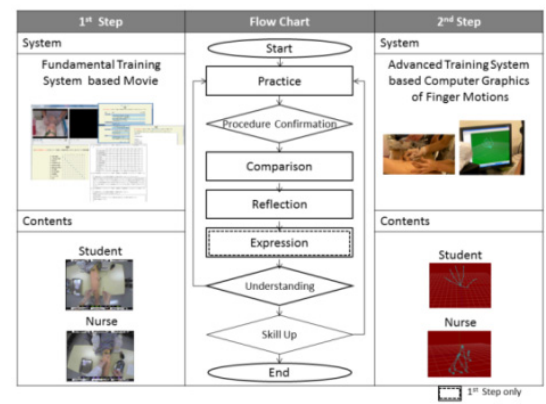

Fig. 1. New System Model for Nursing Skill Learning Based on Cognition and Technique

In other words, the ideal e-learning system model to perform nursing skills selflearning is a model which, after completing learning in the cognitive domain through spiral learning (the first step from intellectual learning support to skill learning support again to intellectual learning support), learners move on to the second step (technique learning support) in a phased manner. Moreover, we think that other-evaluation that is given by instructors by checking between the first and the second steps, as well as checking self-learning, will engender a reduced sense of loneliness, which is a common pitfall of e-learning, and provide satisfaction with self-learning outcomes in addition to motivation for additional development of learning.

\section{Conclusions}

As described in this paper, we proposed an e-learning system model to support a high level of technique learning, such as "tacit knowledge" and "proficient art" in nursing skills that have been heretofore only learned from experience, and also to enable selflearning, in addition to intellectual learning that deepens procedures and understanding of nursing skills. In the future, we will make improvements to the techniques of the learning support system to facilitate its use.

Acknowledgements. We thank all the people who cooperated with this study. A part of this study was supported by a Grant-in-Aid for Scientific Research (B) from the Ministry of Education, Culture, Sports, Science and Technology, Japan (MEXT; No. 19390548) and a Grant-in-Aid for Challenging Exploratory Research from MEXT (No. 21659500).

\section{References}

1. Aso, Y.: Nursing Art, Igaku-Shoin's Medical Dictionary, 2nd edn., p. 504 (2009)

2. Hagi, Y., Ito, F., Nishibori, Y., Toyoshima, Y.: The experience for newly graduated nurses to learn skills of drip infusion to vein. Bulletin Department of Nursing Seirei Christian University 15, 51-59 (2007) 
3. Inaba, Y., Hanaoka, M.: A Consideration of the Concepts of Nursing Skills: The changes and development seen from nursing textbooks. Kyojugaku no Tankyu 17, 65-88 (2003)

4. Polanyi, M.: The Tacit Dimension. The University of Chicago Press (1966)

5. Majima, Y., Hosoda, Y.: The nursing skill education by visualization materials. Journal of the Educational Application of Information Technologies 9(1), 31-35 (2006)

6. Nagumo, H., Sugawara, M., Satoh, N., Kurai, Y., Koyama, S., Nakano, M.: Nursing Students' Attitude towards E-Learning Materials with Moving Pictures. Bulletin of Niigata Seiryo University 5, 33-48 (2005)

7. Sakyo, Y., Toyomasu, K., Ttsukamoto, N., Nakayama, K., Ozawa, M., Kaharu, C., Yokoyama, M., Yamazaki, Y.: Trial Introduction of e-learning as a Tool for Reviewing Nursing Skills. Journal of St. Luka's Society for Nursing Research 10(1), 54-60 (2006)

8. Holland, A., Smith, F., McCrossan, G., Adamson, E., Watt, S., Penny, K.: Online video in clinical skills education of oral medication administration for undergraduate student nurses: A mixed methods, prospective cohort study. Nurse Education Today (2012) (in press), journal homepage: http: / / www. elsevier. com/nedt (February 16, 2012)

9. Cardoso, A.F., Moreli, L., Braga, F.T., Vasques, C.I., Santos, C.B., Carvalho, E.C.: Effect of a video on developing skills in undergraduate nursing students for the management of perfectly implantable central venous access ports. Nurse Education Today 32(6), 709-713 (2012)

10. Majima, Y.: New evolution of nursing education through e-learning. Nursing and Information $12,58-66$ (2005)

11. Jacqueline, B., Julia, R., Alison, W.: The effect of computer-assisted learning versus conventional teaching methods on the acquisition and retention of hand washing theory and skills in pre-qualification nursing students: A randomized controlled trial. International Journal of Nursing Studies 47, 287-294 (2010)

12. Tanaka, M.: Practical Knowledge: Tacit Knowledge: Boundary Knowledge. Official Journal of the International Council of Nurses 2009 32(4), 12 (Summer 2009)

13. Majima, Y., Soga, M., Maekawa, Y.: Development of an E-learning System to Support Reflectional Nursing Skills Training. Japan Journal of Medical Informatics 30(suppl.), 256-259 (2010)

14. Majima, Y., Maekawa, Y.: Converting Tacit Knowledge into Formal Knowledge in Intravenous Injection Skills: Paying attention to nurses' line-of-sight. In: Proceeding of the 29th Academic Conference Japan Academic of Nursing Science, p. 229 (2009)

15. Maekawa, Y., Majima, Y.: Comparison of Consciousness between Expert Nurses and Nursing Students for Knacks (Tacit Knowledge) in Practicing Intravenous Injection Skills: An interview survey. In: Proceeding of the 29th Academic Conference Japan Academic of Nursing Science, p. 315 (2009)

16. Kozu, T.: Medical Education in Japan. Academic Medicine 81(12), 1069-1075 (2006)

17. Trung, Q.T., Albert, S., Jan Van, D., Pamela, E.W.: Teacher-made models: The answer for medical skills training in developing countries? BMC Medical Education 12, 98 (2012)

18. Majima, Y., Maekawa, Y.: Comparative Analysis of Vein Injection Skill Difference Between Skilled Nurses and Nursing Students, Focus to Radial Motion and Skill Procedures. In: Proceedings of the 33rd Annual Conference of Japanese Society for Information and System in Education, pp. 28-29 (2008)

19. Majima, Y., Soga, M., Maekawa, Y.: Development of an E-learning System to Support Self-learning of Nursing Skills. In: Proceedings of the IADIS International Conference, WWW/INTERNET 2010, pp. 400-402 (2010) 
20. Sakoda, M., Majima, Y., Soga, M., Yasuko, M.: Skill Learning Model for Nursing Students in Intravenous Injection Training. In: Proceedings of the 35th Annual Conference of Japanese Society for Information and System in Education, pp. 28-29 (2010)

21. Sakoda, M., Majima, Y., Soga, M., Yasuko, M.: Evaluation of Skill Learning Support System for nursing Students. Japan Journal of Medical Informatics 30(suppl.), 252-255 (2010)

22. Majima, Y., Sakoda, M., Maekawa, Y., Soga, M.: Evaluation of an E-learning System to Support Self-Learning of Nursing Skills. In: Proceedings of the 19th International Conference on Computers in Education, pp. 523-530 (2011)

23. Majima, Y., Sakoda, M., Maekawa, Y., Soga, M.: Evaluation of Nursing Skills Acquisition of Reflective e-Learning System for Nursing Students by Different Learning Methods. In: The 20th International Conference on Computers in Education, pp. 460-467 (2012)

24. Majima, Y., Soga, M., Maekawa, Y.: Learning Support System by Hand Motion Reproduction for Nursing Skill Training. JSiSE Research Report 26(1), 51-54 (2011)

25. Majima, Y., Maekawa, Y., Soga, M.: Learning Support System Reproducing Finger Movements in Practicing Nursing Techniques. In: Proceedings of the 2012 11th International Congress on Nursing Informatics, pp. 278-282 (2012)

26. Majima, Y., SakodaM., M.Y., Soga, M.: Self-learning Support System Design for Nursing Student and Analysis of Nursing Skill Acquisition Process. IEICE Technical Report 111(39), 65-70 (2011)

27. Dorothy, L., Walter, S.: Deep Smarts. Harvard Business Review 82(9), 88-97 (2004)

28. Norman, D.A.: Things That MakeUs Smart: Defending Human Attributes in the Age of the Machine. Addison-Wesley (1993)

29. Kikuoka, S., Honjo, K., Sugita, H., Nakagi, T., Kawashima, M., Kawaguchi, T.: Qualitative Analysis of Practicing Intravenous Injection Skills by Graduates of a College of Nursing. Learning despite Difficult Situations. Journal of the Japanese Red Cross College of Nursing 19, 11-19 (2005) 